\title{
ETNOGRAFIA SENSORIAL E EXPERIÊNCIA SENSÍVEL: EXPERIENCIANDO A CARNE DO MUNDO
}

Marina Ramos Neves de Castro (iD $\square$ 
Com este artigo pretendo discutir a etnografia a partir de sua prática tendo como objeto quase sete anos de pesquisa - de agosto de 2011 a janeiro de 2018 - em uma feira popular localizada em Belém do Pará, Amazônia brasileira. Parte-se da perspectiva fenomenológica de vivenciar a carne do mundo de Merleau-Ponty e busco observar de que maneira essa carne, essa materialidade, se conforma por meio de formas sociais e à sensibilidade socialmente, intersubjetivamente, partilhada. Nesse processo, coloco em evidência como ocorreu a construção do processo etnográfico feito on foot, a partir de uma observação participante, de perto e de dentro, daqueles elementos e conteúdos que conformam a feira enquanto tal: as pessoas e as coisas materiais e imateriais na sua concretude, ou seja, no momento de suas realizações e as sensibilidades de todas as ordens. Essa prática etnográfica, sensorial e fenomenológica valoriza a sensorialidade e a consciência do pesquisador ao ser afetado pelo mundo da vida.

\section{Palavras-chave: Etnografia Sensorial; Sensibilidades; Feira; Carne do mundo; Amazônia.}

\section{SENSORIAL ETHNOGRAPHY AND SENSITIVE EXPE- RIENCE: EXPERIENCING THE FLESH OF THE WORLD}

\section{ABSTRACT}

In this article we intend to discuss ethnography based on its practice, having as its object almost seven years of research - from August 2011 to January 2018 - in a popular fair located in Belém do Pará, Brazilian Amazon. It starts from the phenomenological perspective of experiencing the flesh of the world and seeks to observe how this flesh, this materiality, conforms through social forms and the sensitivity socially, intersubjectively, shared. In this process, it is evident how the construction of the ethnographic process done on foot took place, based on participant observation, from near and inside of those elements and contents that make up the fair as such: people and material and immaterial things in their concreteness, that is, at the time of their achievements; the sensibilities of all orders. This ethnographic, sensorial and phenomenological practice, values the researcher's sensoriality and conscience when being affected by the world of life.

\section{ETNOGRAFÍA SENSORIAL Y EXPERIENCIA SENSIBLE: EXPERIMENTANDO LA CARNE DEL MUNDO}

\section{RESUMEN}

Con este artículo pretendemos discutir la etnografía a partir de su práctica, teniendo como objeto casi siete años de investigación - de agosto de 2011 a enero de 2018 - en una feria popular ubicada en Belém de Pará, Amazonía brasileña. Se parte de la perspectiva fenomenológica de experimentar la carne del mundo y busca observar cómo esa carne, esa materialidad, se conforma a través de formas sociales y la sensibilidad social, intersubjetiva, compartida. En este proceso, es evidente cómo se llevó a cabo la construcción del proceso etnográfico hecho a pie, a partir de una observación participante, desde cerca y desde dentro, de esos elementos y contenidos que componen la feria como tal: personas y cosas materiales e inmateriales en su concreción, es decir, en el momento de sus realizaciones; las sensibilidades de todos los órdenes. Esta práctica etnográfica, sensorial y fenomenológica, valora la sensorialidad y la conciencia del investigador al verse afectado por el mundo de la vida.

Palabras clave: Etnografía sensorial; Sensibilidades; Feria popular Carne del mundo; Amazonas. 


\section{INTRODUÇÃO}

Gostaria de discutir com este artigo a contribuição da etnografia sensorial e, em geral, de uma Antropologia dos sentidos, para o fazer etnográfico. Parto de uma experiência de pesquisa baseada em uma etnografia on foot realizada na feira do Guamá - localizada no bairro do Guamá, em Belém, Pará -, para discutir a dinâmica fenomenológica da experiência sensorial e sensível do fazer antropológico.

A pesquisa que aqui apresento transcorreu durante os anos de 2011 a 2018, e teve por objetivo compreender como se conformavam as relações de reciprocidade baseadas no gosto - ou na ideia que os trabalhadores e frequentadores dessa feira faziam do que seria o gosto. Este artigo apresenta um campo específico dos resultados obtidos, referentes à etnografia sensorial desenvolvida não somente em campo, mas no processo de construção do conhecimento referente a este trabalho.

Procurei colocar em evidência como ocorreu a construção do processo etnográfico feito on foot (Lee \& Ingold 2006), a partir de uma observação de perto e de dentro (Geertz 1989) daqueles elementos e conteúdos (Simmel 2006) que conformam a feira enquanto tal: as pessoas e as coisas materiais e imateriais na sua concretude, as sensibilidades de todas as ordens; aquilo que, a partir do pensamento de Merleau-
Ponty (1945; 1985), compreende-se como a carne do mundo, pois é a carne do mundo o conteúdo que consubstancia a forma. A forma social, ou seja, a sociação, só é passível de existência com conteúdo, com a substância, com aquilo que lhe dá existência, a carne do mundo.

Meu objetivo era entrar na carne daquele mundo e observar de que maneira ela se conforma, de que maneira ela dá corpo e vida à feira, e, assim, acaba por conformar o objeto de pesquisa do pesquisador a partir de sua própria prática etnográfica, experiência esta de ser afetado (FavretSaada 2012), de cair no mundo da vida (Lebenswelt) (Husserl 2006) e ser completamente envolvido pelas circunstâncias do campo.

Em parte, esta pesquisa se fez on foot (Lee \& Ingold 2006). Andando e coletando imagens, odores, sabores, ruídos, sensações táteis, falas, expressões; coletando também percepções, sensações, sentidos e tentando perceber aquilo que sentimos e não apreendemos de imediato. Minha intenção era perceber e assimilar aquelas sensações que levam a certo lugar, e não a outro; aquelas sensações que chamamos de intuição quando as percebemos - ainda que muitas delas fiquem no estado do traço(Derrida 1994), pois muitas dessas intuições não chegam a se materializar enquanto narrativa, prevalecendo sob as formas de sensação, impressão e intuição. 
A feira da qual falo neste artigo não se limita a um espaço, com limites definidos pela materialidade de um mercado ou de ruas e construções de concreto. Ela atravessa diferentes espaços socioculturais e temporais, conformandose através de interações múltiplas, contínuas e descontínuas, produzindo sociações (Simmel 2006). Compreendemo-la, no processo de produção e conformação dessas sociações, como uma forma social: a forma-feira (Castro 2017). Parto de Simmel para compreender forma social como processo de sociação, ou seja, como o resultado de um processo construído, ininterruptamente, através das relações, das interações que se estabelecem entre os mais diversos elementos e conteúdos (Simmel 2006) presentes num dado contexto social.

Simmel (2006) entende por forma o próprio processo de sociação; e por conteúdo aquilo que a compõe - embora uma forma social possa ser, também, o conteúdo de outra forma social (Simmel 2006). Forma, conteúdo, forma-conteúdo, seriam o que, em meu entendimento, contribui para o desencadeamento e o estabelecimento dos vínculos de reciprocidades. Em minha pesquisa, compreendo que conteúdo e forma se alteram de acordo com as (com)formações que socialmente produzem a feira enquanto tal.

Acompanhando esse pensamento, proponho a pensar a feira por meio de uma estratégia formista, simmeliana, que "pode ser compreendida como um pensamento maleável e plástico, que procura se adaptar às necessidades impostas pelo objeto" (Castro 2017: 171). Dessa maneira, procurei perceber os conteúdos, e/ou a formas-conteúdo presentes na feira, como elementos que contribuem para a conformação da própria vivência na feira pelos indivíduos que participam dessa construção, e que, assim, a vivenciam e a experienciam ${ }^{1}$.

\section{FAZENDO A FEIRA}

A feira do Guamá é um espaço situado no bairro de mesmo nome, o segundo mais populoso da cidade de Belém e se não o mais violento, um dos mais violentos, com 94.610 habitantes, de acordo com o censo de 2010 (IBGE 2010)². Esse espaço se localiza no cruzamento das avenidas José Bonifácio e Barão de Igarapé-Miri com a passagem Mucajás. O epicentro desse encontro são os mercados do

\footnotetext{
1 Entendo a relação entre experienciar e vivenciar a partir do pensamento de Cardoso de Oliveira (2003) quando ele observa que a diferença entre o ato de vivenciar e o de experienciar está no tempo, no tempo da vida do pesquisador em relação aos fenômenos experienciados, pois esse só passa a fazer parte da vivência do pesquisador quando há o tempo, capaz de provocar a fusão de horizontes do pesquisador, e o outro.

2 Possui 94.610 habitantes, de acordo com o Censo de 2010; sendo que 1,65\% pertencem à classe $\mathrm{A} ; 4,43 \%$ à classe $\mathrm{B}$; $12,34 \%$ à classe $\mathrm{C} ; 35,70 \%$ à classe $\mathrm{D} ; 45,88 \%$ à classe $\mathrm{E}$ (IBGE 2010).
} 
Complexo de Abastecimento do Guamá, espaço conhecido como o 'mercado da carne', o 'mercado da farinha' e o 'complexo de industrializados', esse um anexo do 'mercado da farinha'. A feira possui cerca de 451 equipamentos ${ }^{3}$ ou boxes de vendas de mercadorias, mas diversos outros comerciantes informais trabalham por lá, como camelôs, vendedores ambulantes, vendedores de pechincha etc. A feira do Guamá é frequentada por um público variado, em sua maior parte pertencente à camada média baixa e às classes trabalhadoras (CASTRO 2018).

Em um sábado de agosto, corriqueiro, comum, adentro na feira do Guamá. Entro pela área dos açougueiros, caracterizada por seus freezers e expositores resfriados que, além de servirem como espaço de exposição da mercadoria, cumpriam também a função de demarcar os limites entre feirante e freguês - uma fronteira presente em todas as áreas e boxes, mas que, neste setor, em função do aparato de seus equipamentos, ganhava um ar mais demarcado e imponente.

Ali, os corredores não são ocupados com produtos, pois a carne precisa estar dentro do boxe, confinada ao refrigerador, diferente do espaço dos hortifrútis, onde as mercadorias invadem o corredor, não somente fisicamente, mas visualmente. Desta maneira me sinto mais ou menos exposta diante da pouca diversidade de produtos - ali só se vende carne, e carne é vermelha -, e não da quantidade, de elementos exibidos, se comparado, ainda com o ambiente intenso e diversificado da área dos hortifrútis (Castro 2018). O ambiente dos açougueiros nos envolve no vermelho - da carne e do piso, e no branco - presente nos boxes e nas roupas da maioria daqueles feirantes. O vermelho da carne e do piso é acompanhado pelo odor de matéria ferrosa, da carne, que nos invade e acompanha enquanto naquele ambiente.

É intenso, também, o vozerio dos que ali estão, acompanhado pelo barulho de carros, motos, buzinas, sirenes, ônibus e caminhões. Sigo caminhando, imersa em tantas informações, em tantos sons e ruídos, no forte odor ferroso de carne, de vísceras, prosseguindo com minha etnografia que se pretende sensível, sensorial (Pink 2009; 2010), atentando para o fato de que, no Pompilho, o Fox Sabadão promove a Quinta Top dos DJs, como insistentemente informa um carro de som.

As vozes que ali se salientam, geralmente, as vozes dos açougueiros, evidenciam a intimidade que eles têm com o lugar. Essas vozes parecem fazer eco no ambiente, ainda que o espaço esteja 
repleto de gente e de carne. A intimidade entre os açougueiros, entre feirantes e fregueses, é evidenciada pelas pequenas expressões animadas, gentis, outras jocosas e engraçadas:

E aí, papai? O que que o neném manda agora? Comendo aí, né papai?!

O que é, meu amor?

Ei, meu patrão!

Leva dois aí, bebê.

Todas elas expressões quotidianas e corriqueiras que conformam, juntamente com os elementos acima descritos, aquela forma social (Simmel 2006).

Continuo o meu andar, o meu propósito é, também, e principalmente, fazer a feira, e ao fazêla, tirar dessa experiência a minha etnografia. Os sons que se sobrepõem à minha percepção parecem barulho, muito barulho, difícil de discernir.

Ater-se à sensorialidade ${ }^{4}$ pode fazer com que nos percamos dentro dela, dentro dessa mesma sensorialidade que buscamos mapear e entender. Por vezes os ruídos do ambiente, reconhecidamente, barulhenta como todas as feiras, escalam em uníssono sensorial.

Perdida ainda, sem entender se, num sábado a vir, a Quinta Top ocorrerá, ou se seria o contrário: seria numa quinta-feira, igualmente a vir, que o Fox Sabadão fará a sua festa. Tanto faz, penso: será num dia qualquer... Como naquele sábado em que estava - era um sábado - ou como no sábado, a vir, também ele, no qual o seu Mariozinho, um de meus interlocutores, prometia me esperar:

Oh! Meu amor, vou te esperar no sábado.

Essa sobreposição de ruídos é característica das feiras, das muitas que já conheci e experienciei. No entanto, não há somente uma sobreposição de ruídos, mas estavam presentes em minha percepção a sobreposição de diversas informações, dentre elas as táteis, as visuais, as olfativas e as sonoras, além de os processos cognitivos que se formam quando experienciamos o mundo. Dessa maneira, como estabelecer a coerência narrativa com que essas informações processamse em nossa percepção? Penso que é justamente baseando-me em uma perspectiva fenomenológica e hermenêutica, que posso, ao procurar descrever as camadas de sentidos - do corpo e da mente, me aproximar desse objeto e compreender o fenômeno pretendido. Essas informações processadas pelos

4 Ressalto aqui que, quando falo em sensorialidade, falo da capacidade do ser humano em apreender as informações do mundo através dos sentidos, ou seja, através do corpo - aqui e especialmente do corpo no campo de pesquisa. As informações do mundo nos chegam através dos sentidos do corpo, e é através dele que conhecemos o mundo. 
meus sentidos tornaram-se um conhecimento do mundo, da carne daquele mundo, da carne do mundo (Merleau-Ponty 1945).

Percebo que as experiências sensoriais a que estamos submetidos quando mergulhamos na paisagem (Pallasmaa 2010) de um lugar, em um ambiente, no caso, de uma feira, não constituem, por assim dizer, um mero acaso. Não são experiências ocasionais, ou ocorrências, meramente. São experiências que se constituem a partir de elementos e conteúdos disponíveis às pessoas ali presentes na sua vida cotidiana, $\mathrm{e}$ são partes integrantes das estratégias que essas pessoas utilizam na sua pragmática, no uso que fazem das coisas do mundo. Quero dizer que essas experiências sensórias parecem estar presentes nas elaborações de mundo das pessoas.

Dessa maneira, penso ser apropriado a ideia de intersubjetividade (Schutz 2012) para compreender a experiência etnográfica. E descrever essa experiência etnográfica, no âmbito da sensorialidade, constitui-se uma tarefa necessária para ampliar as fronteiras do conhecimento aqui interpostas. Intersubjetividade, termo que vem da fenomenologia, consiste naquilo que pode ser compreendido como uma experiência sensível comum e do comum, partilhada.

Podemos, ainda, compreender a intersubjetividade, para melhor entendimento, como o ambiente ou espaço onde estão nossas mentes, nosso corpo, esses que vivenciam e experienciam o mundo. Ainda compreendê-la como sensibilidade, à medida em que a experiência sensível é, necessariamente, intersubjetiva.

A ideia de intersubjetividade permitiume chegar às pessoas a partir do processo que compreendo como alteridade. Esse processo foi acionado pelas experiências sensoriais, perceptivas, intuitivas e cognitivas de perceber o outro e a mim no/e do lugar. Dizendo de outra maneira, esse conceito me permitiu que eu pudesse compreender o fazer da etnografia como uma experiência sensível. Importante observar que compreendemos por experiência sensível um processo complexo que se conforma por interações nas quais se fazem presentes a exploração e a redescoberta a partir da imersão em experiências variadas e incorporadas. Experiências essas nas quais o pesquisador tem a consciência das percepções sensoriais que atuam na construção de seu conhecimento.

Não obstante, também percebi que não se trata apenas de compreender outra compreensão, porque no exercício desse ato, também acabamos, em primeiro lugar, por interpretar e fazer e, em segundo lugar, por provocar novas compreensões e interpretações desse "outro". A compreensão não é, de forma alguma, uma tarefa estática; é sempre o meio de um caminho - ou melhor, o 
meio percurso do círculo hermenêutico (Gadamer 2006; Ricoeur 1999), sempre em processo de se produzir e de se completar.

Compreendo que quando fiz etnografia estive fazendo aquilo que Pink (2012) chama de etnografia sensorial, que também equivale àquela etnografia que, ao produzir conhecimento (Magnani 2009), se utiliza dos sentidos para apreender e aprender e, assim, poder compreender e interpretar. Nesse mesmo sentido evoco Laplantine (2017), ao observar que

O verdadeiro objeto-sujeito da antropologia, isto é, antes de tudo a etnografia, sempre foram as emoções. A experiência de campo é uma experiência de compartilhar o sensível. Nós observamos, nós ouvimos, nós falamos com os outros, compartilhamos sua própria culinária, nós tentamos sentir com eles o que eles sentem. ${ }^{5}$ (Laplantine 2017: 11)

Da mesma maneira partilho do pensamento de Howes e Marcoux (2006) no que diz respeito ao sensível. Esses autores, a partir de uma leitura de Laplantine, observam que o termo "sensível",

[...] é usado para designar a vida das sensações: as relações que mantemos com as três famílias de sons (a voz, os ruídos e a música que é do som organizado), com os cheiros, os gostos, as percepções visuais e táteis. É este último sentido que nós retemos. ${ }^{6}$ (Howes \& Marcoux 2006: 7).

A partir do que já foi colocado, ao fazer a etnografia a que me propus, utilizei todos os sentidos do qual disponho, ainda que sem consciência total ou plena do processo, mas me pautando pelas experiências sensoriais que vivenciei no campo, sem, no entanto, esquecer que, também, somos pautados pelas nossas vivências pretéritas que dialogam intersubjetivamente com as vivências e experiências presentes.

Assim, penso que a experiência social sensível e partilhada, essa intersubjetividade (Schutz 2012) que também pode ser chamada de sensibilidade, contribui para e nas experiências etnográficas.

Quando falo em sensibilidade, busco referir não somente a experiência particular de um indivíduo, tampouco o estado de atenção que alguém tem em relação a alguma coisa, no sentido de ser sensível a isso, ou àquilo. Refiro-me a uma experiência social de sentir-junto-com-outros, de partilhar de um mesmo conjunto de vivências e experiências

5 Como no original: 'Le véritable objet-sujet de l'anthropologie, c'est-à-dire d'abord de l'ethnographie, a toujours été les émotions. L'expérience du terrain est une expérience du partage du sensible. Nous observons, nous écoutons, nous parlons avec les autres, nous partageons leur propre cuisine, nous essayons de ressentir avec eux ce qu'ils éprouvent" (Laplantine 2007: 11). Trad. livre da pesquisadora.

6 Como no original: " [...] est utilisé pour désigner la vie des sensations: les relations que nous entretenons avec les trois familles de sons (la voix, les bruits et la musique qui est du son organisé), avec les odeurs, les goûts, les perceptions visuelles et tactiles. C'est ce dernier sens que nous retenons." (Howes \& Marcoux 2006: 7). Trad. livre da pesquisadora. 
sensíveis. Trata-se, como acima colocado, de uma experiência intersubjetiva, no sentido que o referencial fenomenológico, particularmente Schutz (2012) e Ricoeur (1999), dão a esse termo, ou seja, como substrato da vida quotidiana.

Importante salientar, ainda, que quando falo em abordagem fenomenológica me refiro à disposição de procurar evidenciar as camadas de sentidos presentes na vida cotidiana da feira, naquela carne do mundo. Essa disposição está presente tanto na arqueologia, de maneira denotativa, como na fenomenologia, de maneira conotativa. Tematizo, assim, a Fenomenologia e suas camadas de sentido, e a Arqueologia e sua camadas empíricas. Ambas fazem escavações, e nesse sentido fazemos a analogia entre ambas, e chamo-a de uma abordagem fenomenológicaarqueológica, o que seria, em minha compreensão, aquela que se propõe a escavar os sentidos do mundo da vida e da carne do mundo.

Assim, procuro escavar, desconstruir e desvelar, o quanto possível, os substratos dessas camadas de sentidos que conformam a feira. Deste modo, talvez consiga compreender e interpretar os sintomas daquilo que se concretiza na feira, aquilo que se dá a ver, e que se materializa e se concretiza, e que chamo de carne do (daquele) mundo. Observo como as camadas e os vestígios encontrados, através das percepções sensoriais do pesquisador - ainda que observando o outro e tentando escavar os sentidos do outro - conformam uma escritura que nos delineia uma forma de estar junto, uma forma social evidenciada através dos sentidos, das sensações e percepções experienciados no campo.

\section{ESTRATÉGIAS DE CAMPO OU ESTRATÉGIAS ETNOGRÁFICAS}

Procurei conduzir minha investigação dessa forma social, a forma-feira (Castro 2017), por meio de uma inspiração sensorial, procurando dialogar com a etnografia sensorial (Pink, 2009; 2010) e com a antropologia dos sentidos (Howes 2010) para construir uma percepção etnográfica da feira do Guamá. Essa postura e procedimento me permitiu a possibilidade de construir novas visões de mundo a partir de uma abordagem etnográfica vivida e partilhada, compreendida como uma coprodução de conhecimento, com aqueles atores sociais, meus interlocutores, e coisas que fazem parte do fenômeno interpretado.

A etnografia sensorial que procurei desenvolver demandou alguns arranjos em relação às práticas etnográficas mais tradicionais. Gostaria de mencionar algumas de minhas escolhas para tornar mais clara minha argumentação.

Andando e "fazendo a feira" pretendi escapar da lógica cartesiana - aquela que tradicionalmente separa sujeito e objeto - para melhor adentrar e 
compreender aquela carne do mundo constituída pelo outro, meu interlocutor. Eu acreditava que ao andar, caminhar, ouvir, sentir deveria fazer o exercício de valorizar as sensações - compreendendo por tal tudo aquilo que não conseguíamos, eu e meus interlocutores, externalizar de maneira racional, objetiva, ou que fizesse algum sentido a essa lógica que conforma nossa forma convencionada de ver o mundo. Ou seja, fui à feira com a disposição de um freguês ordinário, aquele que vai à feira para "fazer a feira", escolhendo o melhor produto - a melhor fruta, o melhor tempero - por meio dessa disposição sensorial do tocar, sentir o cheiro, olhar, estar ali com o corpo todo; também por meio da interação - estado inerente ao ato de sentir - cultivando as reciprocidades.

Andar pela feira "fazendo a feira", nessa etnografia on foot (Lee \& Ingold 2006) - eis o que definiu minha postura e minhas escolhas teóricas e metodológicas. Isso talvez resuma minha abordagem, afinal, procurei sempre andar, parar aqui e ali, me predispondo a conversar com todos e todas, ouvindo histórias de vida e procurando compreender como a feira é sentida, percebida, vivida e construída na sua vida quotidiana das pessoas que a frequentam. Ia à feira para "fazer a feira" e, assim, efetivamente, construía minha aproximação para introdução do diálogo, para minha apresentação ao feirante e, também, adquiria o que de melhor o local podia me oferecer, suprindo minha despensa e proporcionando a alimentação necessária para minha família. Além do que, para mim, era mais barato comprar na feira do Guamá do que em qualquer outra feira de Belém, mesmo na do Ver-o-Peso, pois, como observou dona Raimunda, "Aqui, mana, é muito mais barato. Não dá nem pra comparar!’” numa ocasião em que eu comprava a goma, do seu Mário, para fazer tapioquinha.

Para ajudar a registrar meu estar no campo participando da conformação daquela carne do mundo - habituei-me a andar, sempre, com um pequeno gravador em formato vertical, digital, pendurado ao pescoço; em meu entendimento

\footnotetext{
7 Dona Raimunda é moradora do bairro desde a infância, aparenta ter mais de 60 anos, e faz salgados e doces por encomenda. Em entrevista realizada no dia 14 de janeiro de 2017, ela fez questão de deixar claro que a feira do Guamá é mais barata do que a do Ver-o-Peso e utilizou como exemplo a "cuba" de 30 ovos. Naquele dia, no Guamá, ela estava comprando a R\$ 8,50, enquanto no Ver-o-Peso, de onde ela acabara de vir, estava custando R\$ 13,00; e no supermercado cerca de $\mathrm{R} \$ 17$ reais.

8 Observo que sempre solicitava ao meu interlocutor a autorização para registrar nossa conversa, evidenciando que o que mais me interessava era registrar não só o diálogo, mas todos os ruídos ou sons do lugar. Dessa forma, eu obtinha o consentimento de meus interlocutores. As raras vezes, talvez uma ou duas, que alguém não me permitiu o registro, o gravador foi desligado.
} 
isso habituaria a mim e ao outro, o frequentador da feira, àquele aparelho, afastando aos poucos qualquer estranhamento ou impedimento entre mim, o gravador e meu interlocutor ${ }^{8}$. De fato, com minha frequência na feira, isto aconteceu de maneira mais rápida e tranquila do que imaginara, e eu me sentia à vontade utilizando aquele aparelho sempre ligado. Acredito que isso acontecia com meus interlocutores. Quando, por vezes, principalmente em um primeiro encontro, meu interlocutor notava o aparelho, ou eu notava que o feirante o tinha observado, achando aquilo estranho, eu logo explicava que eu utilizava aquilo porque eu conversava com muita gente por ali e, às vezes, esquecia “naturalmente”, pois não conseguia gravar/recordar tudo o que eu havia conversado, dessa maneira, o gravador me ajudava a relembrar.

Refiro ao uso desse objeto, na pesquisa de campo, por dois motivos: primeiro, porque a etnografia sensorial, tal como pensada por Pink (2009; 2010), se faz, geralmente, com apoio de equipamento de gravação de áudio ou audiovisual e, segundo, porque a disponibilidade de gravar os sons do ambiente juntamente com o diálogo havido com os interlocutores, permitia uma proximidade maior com a totalidade, ou integralidade, dos estímulos sensoriais presentes no ambiente, permitindo-me o aguçamento da memória quando da escuta para o próprio ato de etnografar.
Usava também uma câmera fotográfica com a qual, vez por outra, pedindo a autorização devida, registrava o ambiente, a mercadoria, algo que me interessasse, ou mesmo o próprio contexto. Vez por outra também levava uma câmera de filmar; o que me permitiu filmar algumas performances, como a do tratamento de peixes por um ou outro peixeiro, a do tratamento de carne por um açougueiro, a composição de um buquê ou a lavagem da feira. Mas também filmei a banalidade do andar pela feira, meu mero andar por ela, por exemplo, buscando experienciar o ambiente na sua banalidade e quotidianidade.

Não usei caderneta, caderno ou papel e caneta para fazer alguma anotação, pois me sentia mais livre para dar atenção ao meu interlocutor, para comprar mercadorias, para cumprimentar e tocar em alguém, para carregar minha sacola de feira; com minhas mãos livres me sentia mais à vontade para estabelecer uma relação contínua com minha atenção toda voltada ao meu interlocutor e ao meu entorno. Efetivamente, eu acreditava que qualquer parada para tomar nota acabaria interferindo na construção de minha relação com aquele a quem eu queria uma aproximação.

Outro procedimento que utilizei foi, logo na saída do campo, transcrever aquilo que eu tinha vivenciado. Dessa maneira, não somente anotava por escrito aquilo que o gravador tinha 
registrado, mas registrava, principalmente, as minhas impressões, ou seja, tudo o que eu havia vivido naquelas últimas horas na feira e que ainda estava vivo em mim: as impressões, as sensações, os odores, as imagens, os sentidos estavam ali ainda vívidos em mim, tudo ainda estava mais intenso em meu corpo e em minha mente. Tentar registrar e expressar aquela vivência seria importante para uma compreensão e interpretação dos fenômenos vivenciados.

Procurei colocar em evidência meu objeto de estudo: as sensações, os sentidos, as vivências e experiências que encontrei na feira ao chegar lá. Procurei evidenciar pela minha etnografia (Geertz 1989; Peirano, 2006) aqueles elementos e conteúdos que conformam a feira enquanto tal, as pessoas e as coisas materiais e imateriais na sua concretude, as sensibilidades de todas as ordens; aquilo que passaria a identificar como sendo a carne do mundo (Merleau-Ponty 1945; 1985) que dá corpo e vida à feira.

\section{PARA UMA COMPREENSÃO DA CARNE DAQUELE MUNDO}

A carne do corpo nos faz compreender a carne do mundo (Merleau-Ponty 1945: 280)

A ideia de uma etnografia sensorial surge no contexto do debate sobre reflexividade no campo, especificamente sobre a natureza reflexiva da etnografia. Essa ideia está presente em Rabinow (2012), no momento em que ele discute o sentido da ideia de "interpretação", com suas nuances e transparências. Também está presente em FavretSaada (2012), quando discute a "não neutralidade" da Antropologia, em Csordas (2012) nas reflexões sobre os temas da empatia e da intuição, bem como sobre a "transmutação das sensibilidades". Ainda está presente em Crapanzano (2012), por meio do seu debate sobre o "encontro" com a alteridade e sobre as "doze generalizações" da antropologia, e em Clifford (1983), na sua discussão sobre o caminho que o antropólogo faz entre a experiência e a interpretação.

Todos esses autores, em alguma medida, discutem a respeito da dinâmica sensível e intersubjetiva presente no campo etnográfico, observando que ela produz alguns fenômenos centrais na natureza da reflexão antropológica, fenômenos como empatia, intuição, emoções, encontro e polifonia. Sugerem todos eles, também em alguma medida, que é necessário prestar mais atenção para os efeitos da sensorialidade e da percepção no processo etnográfico.

Efetivamente, trata-se, na verdade, da chegada à reflexão antropológica, de um debate já importante no pensamento de Simmel (2006), 
Weber (2009) e na Fenomenologia. Em relação a essa última, um debate presente na sua geral disposição interpretativa, mas, particularmente, na fenomenologia "sensível" de Merleau-Ponty.

A questão da sensibilidade é fundamental na obra de Merleau-Ponty (1985). Ela se coloca no fundamento mesmo da sua reflexão, a partir da sua proposição geral de construir uma nova ontologia (nouvelle ontologie); ou melhor, uma nova possibilidade de alcançar e abordar o mundo da vida (Lebenswelt) - conceito que, em Fenomenologia, significa o mundo não metafísico: o mundo propriamente dito, no qual a vida humana ocorre. Merleau-Ponty pretende explorar o que seria o mundo humano - ou melhor, como o mundo é tomado pelos indivíduos - antes de toda operação reflexiva, a qual lança o homem em direção à metafísica. Efetivamente, assim, ele pretende explorar como o mundo é sentido.

Nas palavras de Silva (2012), Merleau-Ponty pretende "desbravar uma experiência selvagem do sensível, do mundo em estado bruto e arcaico antes da reflexão" (Silva 2012: 1), ou seja, um mundo percebido pelo corpo antes mesmo do processo de racionalização. E esse percurso em direção a uma nova ontologia seria estruturalmente sensível, posto que perpassado por um investimento ontologicamente corporal e intercorporal.
Merleau-Ponty explora o logos do mundo sensível, que equivale a uma pragmática do mundo: o mundo conhecido através da sensorialidade do corpo. Porém, superando a perspectiva psicológica clássica, que pensa nos sentidos como mediadores entre a consciência e o mundo natural, MerleauPonty procura perceber o encontro do indivíduo com esse mundo natural como um movimento de transcendência marcado pelo encontro, pelo contato. Por meio do seu corpo, o homem experimenta o mundo. Mas o faz de forma paradoxal, porque esse experimentar o mundo se dá como um duplo movimento: não apenas o de encontrar e sentir o mundo por meio dos sentidos, mas, também, de projetar esse encontro por meio de figurações intencionais. Esse paradoxo decorre do fato de que o corpo que encontra o mundo, por meio dos sentidos, tem uma atitude reflexiva diante do próprio fato de encontrá-lo:

O enigma é que meu corpo é, simultaneamente, vidente e visível. Ele que olha todas as coisas, também pode se olhar e reconhecer naquilo que vê o "outro lado" de sua potência vidente. Ele se vê vendo, toca se tocando, é visível e sensível para si mesmo. Ele é um si não por transparência como o pensamento que só pode pensar assimilando o pensado, constituindo-o, transformando-o em pensamento. Mas é um si por confusão, narcisismo, inerência daquele que vê naquilo que vê, daquele que toca naquilo que toca, do senciente ao sentido (MerleauPonty 1985: 18-19). 
Como se sabe, a base da Fenomenologia é a compreensão de que todo encontro com o mundo da vida - com o mundo da existência quotidiana - é um ato intencional. Intencionalidade seria o fundamento de todo fenômeno. Isso quer dizer que quando encontramos, sentimos algo do mundo, o fazemos com uma mente já carregada de expectativas, que faz com que cada coisa encontrada no mundo não seja algo "puro" de significações, mas sim como um prolongamento de si mesmo. Como diz Merleau-Ponty, "para o ser que está no mundo as coisas, constituem um anexo ou um prolongamento dele mesmo, estão incrustadas em sua carne, fazendo parte de sua definição plena, já que o mundo é feito do mesmo forro que o corpo" (Merleau-Ponty 1985: 18-19).

A extensão entre corpo e mundo constitui a intencionalidade do ato de sentir o mundo. Essa ideia se traduz plenamente na famosa frase: "a carne do corpo nos faz compreender a carne do mundo" (Merleau-Ponty 1945: 280), bem como na sua - menos famosa - frase escrita alguns anos mais tarde, que reproduz o sentido inverso: "carne do mundo, que se pode, enfim, compreender o corpo próprio" (Merleau-Ponty 1964: 304). Trata-se da "síntese de transição" de que fala o filósofo, por meio da qual, a partir do contato sensorial de seu corpo com o mundo, "o 'sujeito que toca' passa ao nível do tocado" (Merleau-Ponty 1964: 176).
O mundo da vida, o Lebenswelt - ou, ainda, o mundo da facticidade do estar no mundo se conforma por intersensorialidade, ou por coesão estética, cabendo especificar que, para Merleau-Ponty, estética, ou aisthesis, significa essa intersensorialidade presente na relação intencional de estar e usar o mundo, inclusive por meio da produção de analogias em relação à sensorialidade das pessoas ao nosso redor: a aisthesis é, também, um sentir-com-outros, um estar no mundo comum.

Assim, a importância é colocada em uma atitude que possibilite a construção de uma pesquisa pactuada entre o pesquisador e o pesquisado, possibilidade que o método dialogal ou a polifonia - inerente ao processo cultural de qualquer sociedade - tome forma na pesquisa, "que a forma emerja por sí mesma impregnando el trabajo del etnógrafo y también la manera de narrar del nativo com el que dialoga el investigador." (Tyler 1991: 190).

Podemos compreender essa prática, ou melhor, essa postura, como uma cultura de pensar, como uma maneira de refletir sobre o objeto estudado - a partir dos locais/referências aos quais o observador/pesquisador se encontra, que "indaga o lugar do pensamento no seu momento histórico" (Waizbort 2000: 44) - o lugar ideológico, político, cultural, dentre outros tantos possíveis a serem mapeados, do pesquisador e do objeto. 
Portanto, uma cultura de pensar que não leva em consideração somente o objeto da pesquisa, mas tão importante quanto o objeto pesquisado é o pesquisador e o processo estabelecido entre ambos. Uma cultura de pensar que não procura a verdade absoluta dos seres e das coisas, mas busca, na interação, a compreensão da vida, a compreensão do sentido das coisas, das relações, àquilo que dá coesão e unicidade às interações, sejam essas coisas, esses sentidos, os mais díspares ou distantes, para assim compreender as relações sociais.

Por outro lado, em outro sentido, mais difícil ainda a articular, todas elas participam do lugar onde se encontram e da época onde elas florescem. E isso é tão verdadeiro do bazar marroquino como de qualquer outro. Como instituição social e, mais ainda, como um tipo econômico, ele compartilha semelhanças cruciais com o chinês, o haitiano, o indonésio, o iorubás, o indiano, o guatemalteco, o mexicano ou o egípcio - para nos atermos aos casos melhor descritos. Mas como expressão cultural, ele tem um caráter que lhe é próprio. ${ }^{9}$ (Geertz 2003: 79-80).

Dessa maneira também compreendo a feira do Guamá, com semelhanças à outras feiras e/ou mercado (ou ainda souks ou bazares); semelhanças essas que se pode perceber ao encontrar uma.

Como exemplo dessas similitudes, observo o encontro (Geertz 2003), o corpo a corpo para a realização dessa relação; mas com particularidades culturais entre si, ou seja, aquelas formas sociais construídas em seu seio transformam um mero consumidor em indivíduos com conexões pessoais e culturais específicas àquela forma.

Observando e interpretando as múltiplas interações que se tocam, que se encontram, estabelecidas em pontilhismos - como em uma pintura impressionista, onde cada ponto, cada universo pontual corrobora para a construção de uma forma, o quadro (Maffesoli, 1995) -, ocorrendo de formas múltiplas e concomitantes, pode-se compreender as valorações estéticas ali encontradas. Essas relações ocorrem nos momentos das trocas, sobretudo das trocas simbólicas privilegiadas pelo estar-junto - do riso, da fala, das posturas corporais, das expressões, dentre outras tantas possíveis a serem abordadas - e mais intensas do que as relações econômicas estabelecidas ocorridas ali.

Pensar o processo seria pensar a relação de todos os elementos que compõem a feira, que a

9 Como no original: "Par ailleurs, en un autre sens, plus difficile encore à articuler, eles participent toutes du lieu où elles se trouvent et de l'époque où elles déploient. Et cela est aussi vrai du bazar marocain que de n'importe quel autre. Comme institution sociale, et, plus encore, comme type économique, il partage des ressemblances cruciales avec le chinois, l'haïtien, l'indonésien, le yoruba, l'indien, le guatémaltèque, le mexicain ou l'égyptien - pour s'en tenir à quelques-uns des cas les mieux décrits. Mais comme expression culturelle, il a un caractère qui lui est propre." (Geertz 2003: 79-80). Tradução livre da pesquisadora. 
envolvem, que a tocam de alguma maneira, mesmo o mais ínfimo detalhe, mesmo o mais ínfimo dos elementos, pois, como observa Waizbort (2000) a propósito desse pensamento em Simmel, "A "forma" do procedimento vale tanto ou mais do que o "conteúdo" a que se chega" (Waizbort 2000: 21). Ou seja, a forma do procedimento determina o resultado obtido, porque ele, o procedimento, em si já é um conteúdo, já é um resultado, um resultado maleável. Somente com uma descrição exaustiva, uma abordagem formista - que pode ser comparada às abordagens mais contemporâneas e mais conhecidas de Paul Ricoeur (1999) e Geertz (1989) -, dos elementos pertinentes ao objeto estudado, é que poderemos nos aproximar do fenômeno em toda a sua complexidade.

\section{À GUISA DE UMA CONCLUSÃO}

A trilha etnográfica é sempre um labirinto, não obstante o necessário horizonte de uma paisagem a apresentar - no caso das etnografias feitas para conformarem teses, dissertações, relatórios e prestações de contas de bolsas e projetos e outras paisagens afins. Recorro a Ingold (2008), mais uma vez, para falar dessas paisagens:

...essas múltiplas 'paisagens' não se referem ao mundo da prática e da produtivamente habitado. Elas se referem aos mundos virtuais criados pela captura das experiências incorporadas e perceptuais da habitação e pela sua devolução, em formas artificialmente purificadas, para interpretação e consumo (Ingold 2008: 2)

Ingold (2008) está falando aqui, como se percebe, da adequação da pesquisa à metodologia.

O excerto é de um texto de 2008 , mas num outro texto, publicado em 2015, ele é mais específico em relação a essa questão:

Ao ser empregada, a noção de
metodologia transforma meios em
fins, divorciando o conhecimento-
enquanto-conteúdo dos modos
através dos quais se conhece, e assim
impondo um fechamento que é a
própria antítese da abertura para o
presente que a pedagogia pobre
oferece. Se uma metodologia rica
nos oferece conhecimento pronto, a
pedagogia pobre abre nossas mentes
para a sabedoria da experiência. Uma
pertence à instituição da escola, e a
outra, ao tempo da scholè; uma ao
dédalo, a outra, ao labirinto (Ingold
2015: 34 ).

Penso que esta pesquisa se situa entre o dédalo e o labirinto, mas ressalto minha sempre presente disposição de, como disse Masschelein (2010), estar "presente no presente". Comentando esse termo, Ingold (2008) observa que

O preço dessa presença é a vulnerabilidade, mas a recompensa é uma compreensão, fundada na experiência imediata, daquilo que está além do conhecimento. É um entendimento a caminho da verdade. É como diz Greig do poeta: conhecendo pouco sobre o mundo, ele vê as coisas elas mesmas (Ingold 2015: 34). 
Aliás, a própria ação de estar no mundo iminentemente, ou seja, na vida cotidiana na qual é possível a imersão no mundo comum dos outros indivíduos, equivale a, repentinamente, se lançar num labirinto. Como mais uma vez diz Ingold (2008), a atenção de uma pessoa quando anda, quando está no mundo e tem uma postura imanente, equivale a de acompanhar "um mundo que não está pronto, que é sempre incipiente, que se encontra no limiar da emergência contínua" (Ingold 2015: 29).

Essa "emergência contínua" lembra o que, para mim, foi a experiência etnográfica de conviver com a feira durante os quase sete anos em que a realizei. Na etnografia sempre estamos à mercê do que acontece:

À medida que o caminho acena, o andarilho se submete, e fica à mercê daquilo que acontece. Caminhar, diz Masschelein (2010: 46), é ser comandado por aquilo que ainda não está dado, mas está a caminho de sê-lo (Ingold 2015: 29).

Espero ter estado presente no presente. Espero ter colocado em evidência os processos de minha experiência sensível na construção deste trabalho pautado por uma etnografia dos sentidos. Embora isso, evidentemente, nem sempre tenha sido fácil...

Não estava ali para fazer uma etnografia daquilo que foi, como observou Laplantine (2017):

Classificado(s), filtrado(s), purificado(s) para que subsista apenas do limpo, do correto e do explícito. [Pois] Somente são dignas de interesse as notas perfeitamente identificadas (em detrimento dos "ruídos"), as faces fotogênicas, as cores brilhantes, como o vermelho flamboyant ou o azul marinho, em detrimento da continuidade de cores mais "indecisas" que oscilam entre o vermelho e azul, como o lilás [lilases nas suas variações]. (Laplantine 2017: 75) ${ }^{10}$

Mas fazer uma etnografia da vida como ela é. Assim insisto em evidenciar aquilo que incomoda, que toca, que nos incomoda e toca, e que está diante de nós, ainda que muitas vezes precisemos negar - seja evitando um corredor com sujeira no meio, com mau odor, com qualquer coisa que possa nos incomodar.

Por outro lado, acredito que o fazer etnográfico que o pesquisador desenvolve ao longo de sua pesquisa de campo procura, ou deve procurar, encontrar uma consciência do seu estar no mundo pautado pelo estar no mundo do outro. Por isso, compreendo que toda etnografia sensorial é um procedimento fenomenológico, pois trata,

10 Como no original: "triées, filtrées, épurées pour que ne subsiste que du propre, du correct et de l'explicite. Seuls sont dignes d'intérêt les notes parfaitement identifiées (au détriment des 'bruits”), les visages photogéniques, les couleurs franches comme le rouge flamboyant ou le bleu marine, au détriment de la continuité de couleurs plus «indécises» oscillant entre le rouge et le bleu, comme le mauve et le grenat." (Laplantine 2017: 75). 
sobretudo, da experiência do pesquisador no mundo do outro, ou seja, ela resulta do procedimento fenomenológico - compreensão/interpretação do outro - daquele que a desenvolve, que a constrói. Esse procedimento, ou postura fenomenológica, é uma tentativa de alteridade resultante da experiência sensível ao ver o outro, ao estudar o outro, ao tentar compreender e interpretar o outro, ou, ainda, estar sensível para as formas através das quais o outro se coloca no mundo.

Assim, entendo, a partir do pensamento de Magnani (2009), que a etnografia é uma interpretação, mas uma interpretação sobre o outro ou sobre o fenômeno que o outro produz - a cultura, dentre de tantas outras possíveis interpretações, como a arte também o é (Castro 2011; 2017).

\begin{abstract}
...a etnografia é uma forma especial de operar em que o pesquisador entra em contato com o universo dos pesquisados e compartilha seu horizonte, não para permanecer lá ou mesmo para atestar a lógica de sua visão de mundo, mas para, seguindoos até onde seja possível, numa verdadeira relação de troca, comparar suas próprias teorias com as deles e assim tentar sair com um modelo novo de entendimento ou, ao menos, com uma pista nova, não prevista anteriormente (Magnani 2009: 135).
\end{abstract}

Dessa maneira, também partilho do pensamento de Favret-Saada (2005) sobre o afetamento que o pesquisador sofre em campo, pois o que se passa no campo quando somos afetados

\begin{abstract}
...é literalmente inimaginável, sobretudo para um etnógrafo, habituado a trabalhar com representações: quando se está em tal lugar, é-se bombardeado por intensidades específicas (chamemolas de afetos), que geralmente não são significáveis. (Favret-Saada 2005: 159).
\end{abstract}

Ser afetada é uma situação a qual demoramos certo tempo para nos darmos conta ou, por assim dizer, respondermos, compreendermos, ou melhor, nos percebermos a nós mesmos.

Importante ainda observar que partilho do entendimento de Favret-Saada (2005: 158) de que “ser afetado não tem a ver com uma operação de conhecimento por empatia...”, seja essa empatia tomada como um partilhar dos mesmos ideais e sentimentos e/ou das mesmas percepções de mundo, ou empatia enquanto uma comunhão de afetos, ou ainda das antipatias construídas ou encontradas no campo. Ser afeto significa a capacidade de se estabelecer em interação no campo - e tudo que ele traz com ele - de “mobiliza(r) ou modifica(r) meu próprio estoque de imagens, sem, contudo, instruir-me sobre aquele dos meus parceiros." (Favret-Saada 2005: 159). Ser afetada é cair no mundo da vida, é ser inautêntico (Castro 2015; 2017) é ser completamente envolvido pelas circunstâncias do campo, é quando "não podemos narrar a experiência; no momento que narramos não 
podemos compreendê-la” (Favret-Saada 2005: 160), precisamos de tempo para podermos assimilá-la e, quiçá, interpretá-la, pois nela, e dentro dela, estávamos perdidos. E nesse lá estar, submersos, criamos dispositivos que engendram a reciprocidade! O que não implica em identificar-se com o nativo, mas implica sim, em trocarmos impressões, sensações, percepções e expressões, afetos e desafetos, e isso é ser recíproco. É também por essa questão que uma etnografia sensorial é aquela que mais nos aproxima dos fenômenos a serem compreendidos e interpretados, promovendo a possibilidade de uma construção do conhecimento a partir da consciência do próprio corpo em contato com o mundo, na carne do mundo, no campo. 


\section{REFERÊNCIAS}

Cardoso de Oliveira, R. 2003. Sobre o pensamento antropológico. 3. ed. Rio de Janeiro: Tempo Brasileiro.

Castro, F. F. 2015. Intencionalidade, experiência banal e comunicação: esboço de prospecção fenomenológica do cotidiano. Logos 22 (2): 58-70.

Castro, M. R. N. 2017. Aportes teóricos para pensar a feira enquanto forma social. Revista Sociais $e$ Humanas 30 (2).

Castro, M. R. N. 2018. Socialidades e sensibilidades no quotidiano da Feira do Guamá: uma etnografia das formas sociais do gosto. Tese de Doutorado, Programa de Pós-Graduação em Antropologia, Universidade Federal do Pará, Brasil.

Castro, M.; Castro, F. 2016. Mercado, forma, don: Asimetrías de la sociación en un mercado en Belém (Amazonia). Cuadernos de antropología social 44.

Castro, M.; Castro, F. 2017. No emaranhado do Guamá: trajetos etnográficos numa feira de Belém. Ponto Urbe 20.

Clifford, J. 1991. Introducción: Verdades parciales, in Retóricas de la Antropología. Organizado por Clifford, J., e G. Marcus. Retóricas de la Antropologia. Madri : Ediciones Júcar. p. 25-60.

Clifford, J. 1983. On ethnografic authority. Representations 2: 118-146.

Crapanzano, V. 2012. At the heart of the discipline: Critical reflections on fieldwork, in Ethnographic fieldwork: An anthropological reader. Editado por Antonius, C.G.M., J. A. Sluka, e R. Sluka, pp. 547562. Malden: Blackwell.

Csordas, T. J. 2012. "Intuition, revelation, in Ethnographic fieldwork: An anthropological reader. Editado por Antonius, C.G.M., J. A. Sluka, e Sluka R., pp. 540-546. Malden: Blackwell.

Derrida, J. 1994. A voz e o fenômeno. Rio de Janeiro: Jorge Zahar.

Favret-Saada, J. 2012. The way things are said, in Ethnographic fieldwork: An anthropological reader. Editado por Antonius, C.G.M., J. A. Sluka, e Sluka R., pp. 528-539. Malden: Blackwell.

Favret-Saada, J. 2005. Ser afetado. Caderno de Campo 13: 155-161. 
Gadamer, H.-G. [1986] 2006. Vérité et méthode. Paris: Le Seuil.

Geertz, C. 2003. Le souk de Sefrou. Sur l'économie du bazar. Saint-Denis: Ed. Bouchene.

Geertz, C. 1989. A interpretação das culturas. Rio de Janeiro: Ed. LTC.

Howes, D. e Marcoux, J. 2006. Introduction à la culture sensible. Anthropologie et Sociétés 30 (3) : 7-17.

Ibge. Instituto Brasileiro de Geografia e Estatística. 2010. Censo 2010: Pesquisa de orçamentos familiares. Rio de Janeiro: IBGE. http://www.ibge.gov.br/home/estatistica/população/condicaodevida/ pof/2009_2009/de_faul.s_html (acesso em 8 ago. 2021).

Ingold, T. 2015. O dédalo e o labirinto. Caminhar, imaginar e educar a atenção. Horizontes Antropológicos 21 (44): 21-36.

Ingold, T. 2008. Pare, Olhe, Escute! Visão, Audição e Movimento Humano. Ponto Urbe 3.

Laplantine, F. 2017. Le social et le sensible : introduction à une anthropologie modale. Paris: Téraèdre.

Magnani, J. G. 2009. Etnografia como prática e experiência. Horizontes Antropológicos 15(32): 129-156.

Maffesoli, M. 1995. La Transfiguration du politique. Paris : La Table Ronde.

Merleau-Ponty, M. 1945. Phenomenologie de La perception. Paris: Gallimard.

Merleau-Ponty, M. 1964. Le visible et l'invisible. Paris: Gallimard.

Merleau-Ponty, M. 1985. L'oeil et l'esprit. Paris: Gallimard.

Masschelein, J. 2010. The idea of critical e-ducational research - e-ducating the gaze and inviting to go walking, in The possibility/impossibility of a new critical language of education. Editado por GurZe'ev, I., pp. 275-291. Rotterdam: Sense Publishers.

Pallasmaa, J. 2010. Le regard des sens. Paris: Éditions du Linteau.

Pará. Anuário Estatístico do Município de Belém. 2011. Belém: Prefeitura Municipal de Belém.

Peirano, M. 2006. A teoria vivida. Rio de Janeiro: Jorge Zahar Editora.

Pink, S. 2009 [2017]. Doing Sensory Ethnography. London: SAGE Publications Ltda. 
Pink, Sarah. 2010. What is Sensory Ethnography. National Center for Research Methods. https://www. ncrm.ac.uk/resources/video/RMF2010/pages/18_Sensory.php (acesso em 20 de maio, 2020).

Rabinow, P. 2012 [1997]. Fieldwork and Friendship, in Morocco, in Ethnographic Fieldwork: An Anthropological Reader. Editado por A. C. G. M. Robben, J. A. Sluka, pp. 520-527. Malden: Blackwell. Ricoeur, P. 1999. Teoria da interpretação: o discurso e o excesso de significação. Lisboa: Edições 70.

Schutz, A. 2012. Sobre fenomenologia e relações sociais. Petrópolis: Ed. Vozes.

Silva, C. A. F. 2012. O retorno ao mundo da vida: Merleau-Ponty, leitor de Husserl. Revista Filosófica de Coimbra 41(1): 11-32.

Simmel, G. 2006. Questões fundamentais da sociologia. Rio de Janeiro: Zahar.

Tyler, S.1991. Etnografia postmoderna: desde el documento de lo oculto al oculto documento, in Retóricas de la Antropologia. Organizado por J. Clifford, e G. Marcus, pp. 183-204. Madri: Ediciones Júcar.

Waizbort, L. 2000. As aventuras de Georg Simmel. São Paulo: Edições 34.

Weber, M. 2009. Economia e sociedade. Brasília: Editora da UNB. 